\title{
Mathematical thinking skills, self-concept and learning outcomes of 12-year-olds visiting a Mathematics Science Centre Exhibition in Latvia and Sweden
}

\section{H. Salmi, M-P. Vainikainen and H. Thuneberg}

Abstract

Keywords
Teaching mathematics in informal settings is a relatively new phenomenon, but it has gained more attention due to the recent changes in the society. The aim of the present quantitative study was to compare the learning outcomes of Latvian and Swedish 12-year-olds when they visited a science centre mathematics-art exhibition originally designed in Estonia. The results showed that in general, prior knowledge of the exhibition contents was the strongest predictor of post-test results in both countries but that mathematical thinking skills and self-concept had a small added value in explaining the post-test results. The results of the study give some of the first pieces of evidence of the effectiveness of out-of-school mathematics teaching in a science exhibition context, providing a good basis for further studies.

Informal learning; Science centres and museums; Science education

Teaching mathematics in informal settings is a relatively new phenomenon, but it has recently gained more attention [Salmi, 2011; Fenyvesi, 2012; Vainikainen, Salmi and Thuneberg, 2015]. The increasing importance of mathematically structured systems, patterns and models has a fundamental impact on our experience of everyday life, and a particular significance for all digitized societies [Fenyvesi, Koskimaa and Lavicza, 2015]. Resnick [1987] suggests that out-of-school learning environments would be useful particularly for weaker learners, both due to the practice-oriented tool manipulation approach and contextualised reasoning instead of mentation and symbol manipulation.

However, there is little research on the actual learning outcomes of teaching mathematics in a science centre setting and with how pupils on different performance levels benefit from it. Also, when a science centre exhibition designed within one educational system is transferred to another country with different curricular goals, it is unclear if the learning outcomes are comparable. Therefore, the aim of this study was to compare the learning outcomes of Latvian and Swedish 12-year-olds when they visited a mathematics exhibition [Discover the Art of Math, 2014] originally designed in Estonia. The exhibition was delivered by "4-D -mathematics" by the Dutch mathematician and artist Theo Jansen [Jansen, 2007].

To control the possible initial differences in the mathematical competences of the children, the pupils took first a mathematical thinking skills test that has been 
shown to be relatively culture free. For development of topic-specific knowledge on the content areas of the exhibition was then assessed by a pre-test - post-test procedure. The impact of mathematical self-concept on learning, and possible cultural differences in it are also compared.

\section{Out-of-school mathematics education}

Learning from informal sources and in an out-of-school environment has been found to be effective and motivating [Osborne and Dillon, 2008; Fenichel and Schweingruber, 2010]. This quantitative study is based on the theories and literature findings bridging the gap between formal education and informal learning. As a starting point for this development was the UNESCO report Learning to Be - The Faure Report in 1968 [Faure et al., 1972]. Two other classical books describing this phenomenon are Deschooling Society by Illich [1971] and The Unschooled Mind by Gardner [1991]. Informal education has often been regarded as the opposite of formal education. Since the 1990s, however, informal education has become a widely accepted and integrated part of school systems [Salmi, 1993; Salmi, 2012; Fenichel and Schweingruber, 2010].

The link between formal education and informal learning has been the development of computer and communication technologies, which profoundly have altered our every-day lives, and since 2000s', great promises for education and cost-effective informal learning has aroused, too. As the thematic issue of the Science $(1 / 2009)$ suggested under the headline "Making a Science of Education" demanded a great deal of high quality research by focusing on the utilization and effects of the new technologies in both, school and informal learning environments as well [Salmi, Kaasinen and Kallunki, 2012]. A huge amount of information, especially about modern phenomena like the recent developments in the mathematics, science and the new technologies, is obtained in a personal way from family, friends, and peer groups. Furthermore, the roles of television, libraries, magazines, and newspapers are also essential for public understanding of science. Museums and science centres have regularly had increased numbers of visitors during the last decades [Dillon et al., 2006]. Despite this development, there has been less theoretical or empirical research in the informal sector [Osborne and Dillon, 2008]. ICT- and web-based learning has challenged and changed the vision of traditional formal education [Salmi, 2011; Salmi, 2012].

Out-of school education often uses informal education resources like web-sites, portals, science exhibitions, and natural parks for formal education. It forms a pedagogical link between formal education and informal learning. Science centre education is one form of out-of-school education. [Tan Wee Hin and Subramaniam, 2003; Rennie et al., 2003; Braund and Reiss, 2007; Salmi, 2012; SINUS, 2012].

Informal learning have traditionally been used in, for example, the teaching of biology [Falk, 1982], geography learning [Rennie et al., 2003], science education [Braund and Reiss, 2004], museology solutions [Melton, Feldman and Mason, 1936], and art education [Newsom and Silver, 1978]. To advance public understanding of science, new forms of education were actively sought [Crane et al., 1994; Rennie et al., 2003]. Learning does not take place only in the actual world of school, but in the presented world of nature, parks, yards, science centres, gardens, and the 
media, as well as through the virtual worlds of the internet and social media [Braund and Reiss, 2007; Frantz-Pittner, Grabner and Bachmann, 2011; Salmi, 2011].

There has been few activities related to mathematics education and learning in informal learning settings including science centre exhibitions [Curtain-Phillips, 1999; Forman and Steen, 2000; Persson, 2000; Vainikainen, Salmi and Thuneberg, 2015; Fenyvesi, Koskimaa and Lavicza, 2015]. The international mathematics event BRIDGES consisting of exhibitions, live science demonstrations, interactive lectures, films, workshops, and art performances, arranged annually is one of the few role models for this type of public understanding of mathematics exhibition and activities [BRIDGES, 2014].

BRIDGES-project is one promising example of the adding art complements to the traditional STEM (Science, Technology, Engineering, and Mathematics) education and turns it to STEAM thus bringing art as one new element in the learning process. There is not very much research evidence yet, but some researchers [White, 2014] even claim that this change of the paradigm would be as crucial as the effect of the Sputnik-phenomenon [see Hein, 1990; Salmi, 2003] had in the late 1950s. The conception of STEM (Science, Technology, Engineering and Mathematics) integration needs to be complemented with the arts and need to put a strong emphasis on humanities. There are certain options to take up Art as well, and need to be changed to STEAM. [Fenyvesi, Koskimaa and Lavicza, 2015].

There are some evidence-based mathematics education research results encouraging STEAM-type of activities [Fenyvesi, 2012; Fenyvesi, Koskimaa and Lavicza, 2015]. As an example, the survey concerning students' ( $N=2598)$ attitude towards mathematics and mathematics education showed clear evidence for the alienation of mathematics from the everyday concerns of the youth. Based on that evidence Fenyvesi, Koskimaa and Lavicza [2015] proposed experience-centered education of mathematics through hands-on, arts, playful learning, and digital activities as an effective way to grasp the complex relationship between mathematics attitudes, joy of learning and social situation.

There is also evidence on the effectiveness of cooperative learning methods in mathematics education [Slavin, Lake and Groff, 2009]. Even though a science centre visit is not usually structured using cooperative learning as a starting point, however, this "Discover the Art of Math" exhibition was designed for both cooperative and individual learning. Thus, it did not differ from the programmes evaluated by Slavin and colleagues in their extensive meta-analysis as many elements of the cooperative programmes were present when children explored mathematical phenomena together in a science centre context. The review of Slavin and colleagues showed that the programmes that were found to be effective seemed to work equally well also with disadvantaged and minority pupils, and they therefore suggested the use of such programmes especially when achievement gaps are to be reduced. Therefore, in the present study the main emphasis is on evaluating how out-of-school mathematics education in a science centre context could benefit pupils whose cognitive competences are lower than their age-mates. The comparisons are made across three language groups in two countries to ensure that the findings are not too context-specific and can be generalised to other countries. 
There are different theoretical approaches for studying children's cognitive development, but perhaps the most comprehensive one is the theory of the architecture of the mind proposed by Demetriou and his colleagues [Demetriou, Spanoudis and Mouyi, 2011]. It integrates findings and concepts from psychometrics [e.g., Carroll, 1993; Gustafsson, 1984], the psychology of cognitive development [e.g. Piaget, 1972; Shayer, 1979] and cognitive psychology. The theory has a strong developmental perspective but it also acknowledges the individual differences in children's cognitive competences. Moreover, it emphasises the role of education in enhancing the effective use of the developing competences. This makes it a good framework for the present study, which evaluates the learning outcomes of children visiting a mathematics exhibition in a science centre in different countries.

Demetriou's model [Demetriou, Spanoudis and Mouyi, 2011; see also Adey et al., 2007] includes both general mechanisms and specialised structural systems for different domains of knowledge or relations. The specialised structural systems of spatial, verbal, quantitative, categorical, causal and social reasoning are coordinated by the representational capacity system, which is a more elaborated version of the traditional understanding of working memory [cf. Baddeley and Hitch, 1974]. It interacts with the inference system, which is responsible for connecting and integrating information and operations according to the selected goal. The specialised structural systems are considered as autonomous domains of understanding and problem solving, and they are monitored and regulated by the consciousness system. They may develop at different rates but they are also constrained by the development of the other, higher-level systems [Adey et al., 2007] and can all be trained by means of interventions and education [Demetriou, Spanoudis and Mouyi, 2011]. There is evidence that for children at about the age of the participants of the present study, mathematics achievement and achievement growth is longitudinally predicted by both earlier domain-general abilities - the functioning of the inference system and representational capacity - and competencies that are unique for learning mathematics [Geary, 2011; see also Duncan et al., 2007] Therefore, they both need to be taken into account when learning in a science centre context is studied.

The specialised structural system for quantitative reasoning deals with quantitative variations and relations in the environment [Demetriou, Spanoudis and Mouyi, 2011]. Like all structural systems, quantitative thought is organized on three levels: core processes, mental operations, and knowledge and beliefs. According to the theory, the core processes of subitization, counting, pointing, bringing in, removing and sharing require the mental operations of monitoring, reconstruction, execution and control of quantitative transformations, and the four arithmetic operations. The knowledge and beliefs cover factual knowledge about the quantitative aspects of the world and algebraic and statistical inference rules. By the age of eight years, most children have achieved the basic understanding of number concepts and quantitative dimensions, and by the age of ten they can construct simple mathematical relations. Proportional reasoning skills and coordination of symbolic structures develop usually by the age of 12 years. These skills are specific for quantitative thought and they together with the developing representational capacity - working memory - and the inference system form the basis for learning mathematics. 


\section{Mathematical self-concept and learning}

Mathematical self-concept refers to pupils' perception of their own capacity and performance level in mathematics. The conceptualisation used in the present study is based on the theory originally proposed by Shavelson in the 1970s [see Marsh, 1990]. The theory divides self-concept into academic and nonacademic components, and the academic self-concept is further divided into self-concepts in particular subject areas (e.g., mathematics, English). The model was later revised by Marsh and Shavelson [see Marsh, 1990] who identified two higher order factors, verbal and mathematical academic self-concepts besides the general academic one. There is a large body of evidence showing that mathematical self-concept is positively related to performance in different countries [e.g. Chiu and Klassen, 2010; Marsh, Byrne and Shavelson, 1988], but there are somewhat controversial results of whether it really influences performance when performance differences have been controlled for. It seems that in some contexts, optimistic self-beliefs can improve performance through commitment and perseverance [cf. Bandura, 1997], but a large discrepancy between actual capacities and self-beliefs can be harmful, too [Chiu and Klassen, 2010]. Chiu and Klassen [2010] observed in their study that despite the positive connection between mathematical self-concept and performance in most of the more than 30 countries participating in the PISA 2003 study, there were clear cultural differences, as well. The link between mathematical self-concept and performance was stronger in wealthier countries, and there were clear differences in the average level of mathematical self-concepts between countries, which did not necessarily reflect the differences in the country-level cognitive results. In general, Western students in individualistic societies had higher self-beliefs. Regarding the countries participating in the present study, Swedish students' performance was slightly over the OECD average but self-concept slightly below it, whereas for the Latvians it was the other way around [Chiu and Klassen, 2010]. However, since PISA2003the performance of the Swedish students has clearly declined while the Latvians have slightly improved their results [OECD, 2013b]. Even though the Latvians do perform better, their mathematical self-concept has become more negative [OECD, 2013a].

\section{The present study}

The context of this study was a mobile interactive mathematics exhibition [Discover the Art of Math, 2012]. The exhibition was based on and inspired by the works of Theo Jansen, a Dutch artist who has created many projects that involve art, math and technology [Jansen, 2007]. In 1990, he began what he is known for today: building large animals out of animated works that are a fusion of art and engineering - PVC-plastics that are able to "live" on their own. The exhibition consisted of eight interactive, "hands-on" science exhibition objects. The students were allowed to use, test, and explore the exhibition for 45 minutes according their own interest. After that they attended a workshop (also 45 minutes) in which they were building their own structures and creatures of the small "lego" type of pipes and circles. The pupils visited it and participated in experimental learning session in order to acquire knowledge and skills that would support the curricular science learning goals of sixth graders aged 12-13 years old. The individual work was combined into group work by putting together different items. The exhibition guide acted as a tutor, and the classroom teacher was just responsible for practical arrangements. The exhibition was touring from August 2013 to October 2014 in Trollhättan and Stockholm, Sweden and in Cesis, Latvia. 
The general aim of the present study was to find out how comparable results regarding learning outcomes of out-of-school mathematics education are across countries. That is, when the exhibition designed by the Estonian Energiakeskus was taken to Sweden and Latvia with different educational systems and curricular goals, are the learning outcomes and their predictors similar in them. The specific research questions and the hypotheses to be tested were:

Q1: Are the relations between prior knowledge of the exhibition contents, learning outcomes after the exhibition, the more general mathematical thinking skills, and mathematical self-concept similar in the two countries?

H1: In both countries, prior knowledge is the strongest predictor of the post-test result [Thuneberg, Salmi and Vainikainen, 2014]. Mathematical thinking skills are positively related to prior knowledge and they also predict slightly higher post-test scores, indicating that originally more skillful pupils also learn more in the exhibition [Thuneberg, Salmi and Vainikainen, 2014; Vainikainen, Salmi and Thuneberg, 2015]. Mathematical self-concept is positively related to prior knowledge and mathematical thinking skills, reflecting the true differences in the competence. It also produces a small additional effect on the post-test results in both countries.

Q2: Are there differences between the two countries in the performance level regarding mathematical thinking skills, prior knowledge and learning outcomes, and the level of mathematical self-concept?

H2: Latvian pupils perform better than Swedish pupils in both the general and the topic-specific mathematical tasks but they have a more modest self-concept [OECD, 2013b; OECD, 2013a].

The participating school classes were randomly selected from all school classes that expressed their interest in visiting the exhibition. In Sweden, the mathematics exhibition was organised in two different science centres. The first sample from the autumn 2013 consisted of 385 pupils from the Western part of the country, and the second sample from 2014280 pupils from the capital area. In Latvia, 288 Latvian-speaking pupils and 120 Russian-speaking pupils from all over the country participated. The total sample consisted of 1073 pupils ( 518 girls, 535 boys, 20 missing, mean age $\mathrm{M}=12.39$, $\mathrm{Sd}=.99$ ).

\section{Tasks}

\section{Mathematical thinking skills}

The pupils' mathematical thinking skills were measured by two tasks, which were presented to the pupils one week before the science centre visit. The first task was based on the Hidden Arithmetical Operators task by Demetriou and his colleagues 
[Demetriou et al., 1991]. This task was particularly suitable for country comparisons as the underlying quantitative-relational abilities measured by the task have been shown to be relatively universal [Demetriou et al., 1996]. The adapted version of the test has been used by for instance in Vainikainen et al. [2015]. In each of the seven items that were comparable across countries there were one to four hidden operators (e.g., [(5 a 3) b $4=6$. Replace the letters by symbols for addition $(+)$, subtraction $(-)$, multiplication $(*)$ or division $(\div)$ so that the equation is correct. You can only use each symbol once in each equation]). The items were coded dichotomously for a correct answer to all of the one to four operators in the item.

The second task was based on the Invented Mathematical Concepts of Sternberg's Triarchic Test (H-version) Creative Number scale, which has also been previously used for country comparisons [Sternberg et al., 2001]. Pupils had to solve multiple-choice equations where arithmetical operators were conditionally defined depending on the value of the digits they combine (e.g., if $a>b$, lag stands for subtraction, and otherwise for multiplication. How much is 8 lag 5? Options: 40 / 13 / 3 / 14). The eight items of the task were coded dichotomously for the whole equation. The final score for mathematical thinking was calculated by summarising all the 15 dichotomously coded items of the two tasks together.

\section{Pre- and post-test for topic-specific knowledge.}

The knowledge test was developed for the present study based on the content areas of the science exhibition piloted with a smaller Finnish sample (N:76) half a year before the actual data collection started. The test was presented to the pupils approximately one week before the science centre visit and again about 7-11 days after the visit. Pupils were presented with short verbal stimuli followed by one to four statements, and the pupils' task was to judge whether the statements were correct or incorrect. They also had the option to say that they do not know the answer, but for the present study 'don't know' answers were coded as incorrect. All the items were coded dichotomously. Preliminary analyses using Item Response Theory revealed that two very difficult items had a poor discrimination value, so they were omitted from the further analyses. The final test scores for pre- and post-test were calculated by summarizing the remaining 24 items together. The reliability for the pre-test score was $\alpha=.74$ and for the post-test $\alpha=.81$.

\section{Mathematical self-concept.}

Mathematical self-concept was measured by a three-item scale (I am good at maths. / I usually handle even the more difficult math problems well. / Math is very easy for me.) The items were answered on a seven-point Likert-scale $(1=$ Do not agree at all to 7 = fully agree). The scale was based on the theory of Marsh and Shavelson [see Marsh, 1990] and it has been extensively used in Finnish learning to learn assessments [see Vainikainen, 2014]. The reliability of the scale was good $(\alpha=.88)$. An average score of the three items was calculated to be used in path modelling as a manifest variable. 


\section{Statistical methods}

Descriptive statistics were calculated with SPSS22 and item parameters for the preliminary analyses in Mplus. The relations between the variables in the two countries were studied by multiple-group path modelling (SEM) in AMOS22. Since the deviation from normality of all variables was within the recommended limits [Kline, 2005], maximum likelihood estimation was used. The models were considered having a good fit with CFI and TLI $>.95$, and RMSEA $<.06 . \chi^{2}$-values are also reported but due to the sample size significant $\mathrm{p}$-values were to be expected. Additional group comparisons between the pupils on different performance levels regarding mathematical thinking in the two countries were performed by repeated measures ANOVA in SPSS22.

\section{Results}

First, descriptive statistics were calculated for the whole data and for the two countries separately. The means and the standard deviations are presented by country in Table 1.

Table 1. Descriptive statistics of the variables used in the modelling for the two countries.

\begin{tabular}{lrccrc}
\hline Measure & N & Min & Max & Mean & Sd \\
& L $\mid \mathbf{S}$ & L $\mid \mathbf{S}$ & L $\mid \mathbf{S}$ & L $\mid \mathbf{S}$ & L $\mid \mathbf{S}$ \\
\hline Pre-test & & & & & \\
Mathematical thinking skills & $353 \mid 362$ & $1 \mid 0$ & $14 \mid 15$ & $7.19 \mid 4.79$ & $2.99 \mid 2.60$ \\
Mathematical knowledge (pre-test) & $360 \mid 355$ & 0 & $21 \mid 19$ & $11.29 \mid 7.98$ & $3.74 \mid 4.44$ \\
Mathematical self-concept & $346 \mid 346$ & 1 & 7 & $4.12 \mid 5.08$ & $1.50 \mid 1.39$ \\
$\begin{array}{l}\text { Post-test } \\
\text { Mathematical knowledge (post-test) }\end{array}$ & $334 \mid 348$ & 0 & $22 \mid 21$ & $13.22 \mid 9.78$ & $3.90 \mid 4.71$ \\
\hline
\end{tabular}

The values for Latvia and Sweden are separated by a vertical bar.

$\mathrm{N}=$ Number of respondents, Min= Minimum value, Max= Maximum value, $\mathrm{Sd}=$ Standard deviation.

H1: In the first hypothesis we expected that prior knowledge would be the strongest predictor of the post-test result and that mathematical thinking skills would be positively related to both prior knowledge and the post-test scores in both countries. We also expected that mathematical self-concept would be positively related to all the cognitive variables, indicating that the measure both reflects true differences between the pupils but also has a small additional effect on the development of performance in both countries. This hypothesis was tested by specifying a multiple-group path model, in which pre-test scores, mathematical thinking skills and mathematical self-concept were allowed to correlate with each other and they were all used as predictors of post-test scores. As the unconstrained model did not have sufficient degrees of freedom for computing the fit indices, we constrained the path from mathematical self-concept to post-test to be equal across groups. This baseline model fit the data excellently. After that we began to constrain the paths, the correlations, the means and the intercept stepwise to be equal across the groups. The changes in the fit indices are presented in Table 2. 
Table 2. The models for testing the group differences between the two countries.

\begin{tabular}{|c|c|c|c|c|c|c|}
\hline Model & $\chi^{2}$ & $d f$ & CFI & TLI & RMSEA & $p$ \\
\hline $\begin{array}{l}\text { 1. Only mathematical Self-concept - Post-test path } \\
\text { constrained to be equal across groups }\end{array}$ & .083 & 1 & 1.000 & 1.038 & .000 & .773 \\
\hline $\begin{array}{l}\text { 2. Additional constraint on Mathematical thinking- } \\
\text { Post-test path }\end{array}$ & .100 & 2 & 1.000 & 1.039 & .000 & .951 \\
\hline 3. All the paths constrained to be equal & 11.684 & 3 & 982 & .880 & .052 & .009 \\
\hline $\begin{array}{l}\text { 4. Model } 2 \text { constraining the correlation between Math- } \\
\text { ematical thinking and Self-concept to be equal }\end{array}$ & .655 & 3 & 1.000 & 1.032 & .000 & .884 \\
\hline $\begin{array}{l}\text { 5. Additional constraint on the correlation between } \\
\text { Pre-test and Self-Concept }\end{array}$ & 9.7913 & 4 & .988 & .941 & .037 & .046 \\
\hline 6. Model 2 with constraints on all correlations & 15.984 & 5 & .977 & .909 & .045 & .007 \\
\hline $\begin{array}{l}\text { 7. Model 4, Mathematical thinking mean constrained } \\
\text { to be equal }\end{array}$ & 151.501 & 4 & .695 & -.527 & .186 & $<.001$ \\
\hline 8. Model 4, Self-concept mean constrained to be equal & 93.951 & 4 & .815 & .073 & .145 & $<.001$ \\
\hline 9. Model 4, Pre-test mean constrained to be equal & 151.518 & 4 & .695 & -.527 & .186 & $<.001$ \\
\hline 10. Model 4, Post-test intercept constrained to be equal & 28.767 & 4 & .949 & .744 & .076 & $<.001$ \\
\hline
\end{tabular}

$\mathrm{CFI}=$ Comparative fit index, $\mathrm{TLI}=$ Tucker-Lewis index, $\mathrm{RMSEA}=$ Root mean square error of approximation.

The table shows that in addition that there was no country difference in the regression coefficient between self-concept and post-test, constraining the regression coefficient between mathematical thinking and post-test to be equal across countries did not influence the fit indices either. In contrast, constraining the path from pre-test to post-test influenced the fit indices, so there was a statistically significant difference between the countries in how strong the prediction was. Therefore, the further models for testing the differences in correlations and means were based on the second model without the constraint on this particular path. The fourth model shows that the correlation between mathematical thinking and self-concept was equally strong in both countries. In contrast, constraining the two other correlations both deteriorated the fit indices, so there were statistically significant country differences in them. The last four rows of the table show that there were highly significant country differences in the means of all the predictors and in the intercept of the post-test. Therefore, the fourth model was concluded as fitting the data the best. This model is presented in Figure 1, highlighting the statistically significant differences in the regression coefficients and the correlations between the two countries. The observed mean differences will then be analysed in detail when presenting the results regarding the second hypothesis.

The figure shows that just as expected, prior knowledge as demonstrated in the pre-test was clearly the strongest predictor of post-test performance in both countries. However, the prediction was statistically significantly stronger in Sweden compared to Latvia. Mathematical thinking skills were moderately related to pre-test scores in Sweden but not in Latvia, but in both countries they weakly predicted post-test scores beyond prior knowledge. That is, pupils with more developed mathematical thinking skills learned slightly more in the exhibition. Mathematical self-concept also predicted post-test scores weakly but statistically significantly in both countries even when the effects of prior knowledge and mathematical thinking skills were controlled for. Self-concept was as expected 


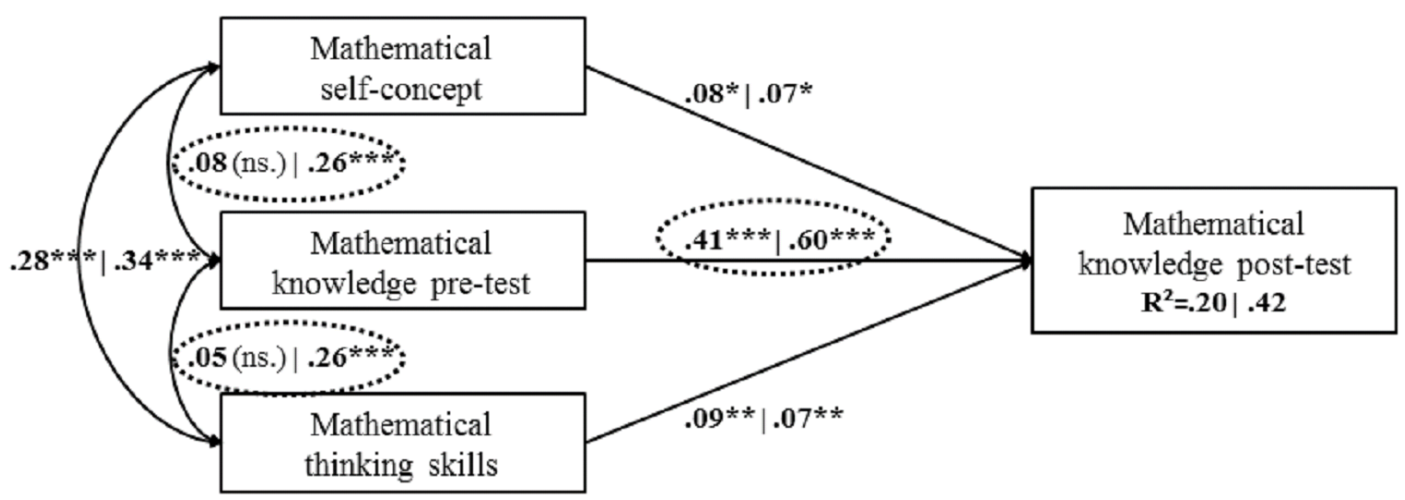

Figure 1. The path model for predicting post-test performance in the Latvian and Swedish samples. The coefficients for Latvia and Sweden, respectively, are separated by vertical bars. The statistically significant differences are highlighted with dotted circles. ${ }^{*} \mathrm{p}<.05,{ }^{* *} \mathrm{p}<.01$, *** $\mathrm{p}<.001$, (ns.) non-significant path.

related to mathematical thinking skills in both countries, but a little surprisingly in Latvia it was not related to the pre-test score. It can be concluded that the first hypothesis was supported only partially due to the weaker-than-expected relations between many of the variables in Latvia.

H2: In the next hypothesis we expected the Latvian pupils to perform better than Swedish pupils in both the general and the topic-specific mathematical tasks.

However, we did not expect this difference to be reflected on the pupils' mathematical self-concept. The model comparisons conducted when testing the first hypothesis showed that there were statistically significant country differences in all variables, including mathematical self-concept. Table 1 shows that here, contrary to the results in all the cognitive variables, the Swedish pupils evaluated themselves more positively than Latvians. The difference was statistically significant $(t=10.108, d f=971, p<.001)$. In regard to that, the second hypothesis was supported.

The country differences in the cognitive variables were studied more closely by dividing the pupils in four groups in both countries based on their performance in the mathematical thinking skills test. The groups were formed by defining quartiles across the whole sample. The numbers of pupils per country per group are displayed in Table 3. The table shows that Latvian pupils were overrepresented in the highest performing group whereas Swedish pupils were overrepresented in the lowest-performing group.

Table 3. Number of pupils in mathematical thinking skills performance groups in the two countries.

\begin{tabular}{lccc}
\hline Group & Latvia & Sweden & Total N \\
\hline Lowest performance & 40 & 237 & 277 \\
Low average performance & 79 & 168 & 247 \\
High average performance & 90 & 134 & 224 \\
Highest performance & 162 & 98 & 260 \\
\hline
\end{tabular}




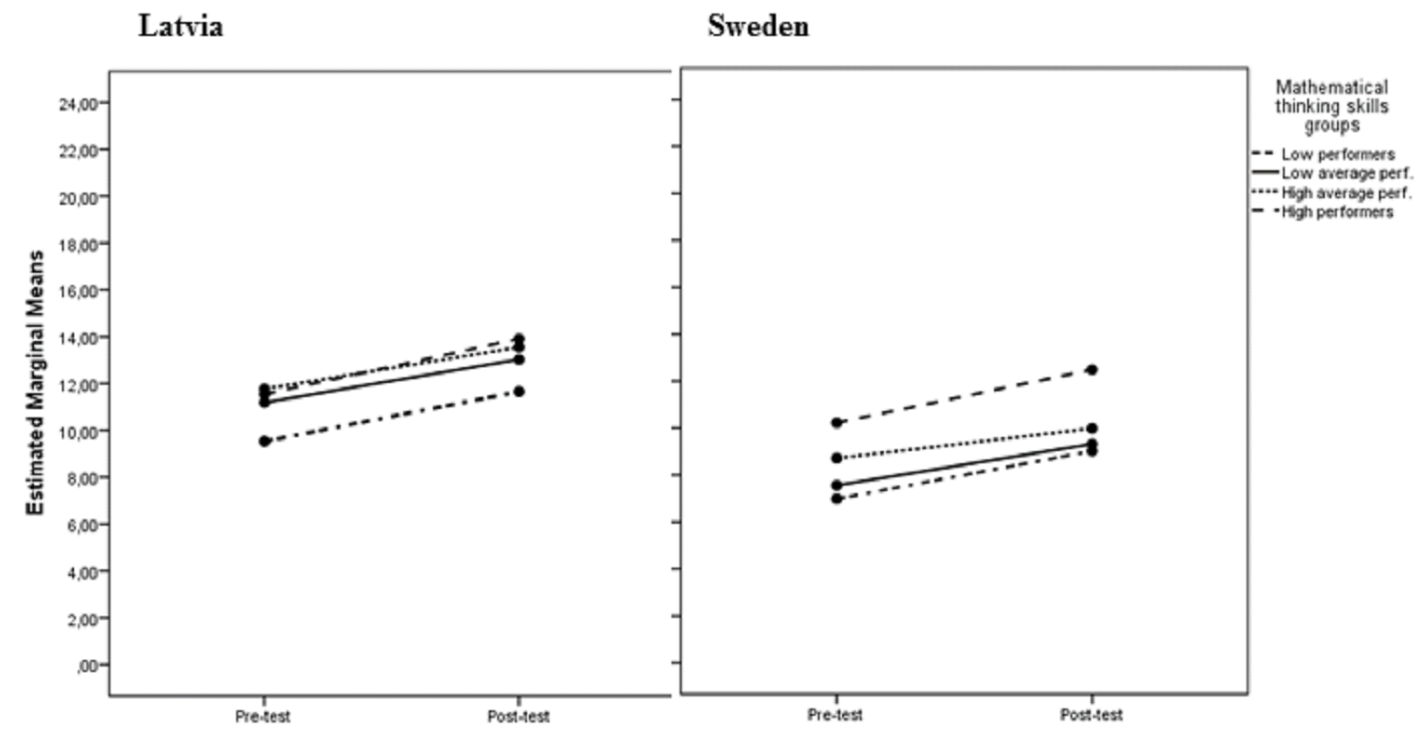

Figure 2. The development of performance in the knowledge test of the groups based on mathematical thinking skills in Latvia and Sweden.

Next, the possible interactions between the country and performance-level grouping in regard to the development of performance in the knowledge test were studied by repeated measures ANOVA. The results showed that the improvement of the performance was statistically significant (Wilks' lambda $=.841, F=151.805$, $d f=1, p<.001)$ and that there were statistically significant differences between the performance groups $(F=15.972, d f=3, p<.001)$ and the countries $(F=90.879, d f=1, p<.001)$. Moreover, there was a weak interaction between the mathematical thinking skills grouping and country $(F=4.076, d f=3, p<.01)$. Thus, performance of pupils in different groups had developed slightly differently in the two countries. The development of performance in the knowledge test of the four groups are presented for the two countries separately in Figure 2.

The figure shows that in all performance groups there was a clear difference in the performance level of Latvian and Swedish pupils so that the Latvian pupils belonging to the lowest-performing group regarding their general mathematical thinking skills had approximately equal prior knowledge and development of the performance than the highest-performing Swedish group. In general, the group differences were in Latvia much smaller than they were in Sweden, and only the lowest performers got considerably lower scores in the pre-and post-tests. This explains also the lower-than-expected correlation between mathematical thinking skills and pre-test, which was observed when testing the first hypothesis. The figure shows also that in Sweden, the highest performing group improved their performance slightly more than the two average groups. However, also the weakest performers learned in both countries, and the differences to the other groups in the improvement were not big. In all, the second hypothesis regarding the country differences in performance was supported. 
The aim of the study was to find out how comparable the results regarding learning outcomes in out-of-school mathematics education are across countries with different educational systems and curricular goals. More specifically, it was studied whether the relationships between prior knowledge of the exhibition contents, learning outcomes after the exhibition, the more general mathematical thinking skills, and mathematical self-concept were similar in the Latvia and Sweden. Moreover, it was studied whether the 12-year-olds of the two countries differed systematically regarding the level of performance and mathematical self-concept. The results showed that in general prior knowledge of the exhibition contents was the strongest predictor of post-test results in both countries but that mathematical thinking skills and self-concept had a small added value in explaining the post-test results. The study also revealed some interesting differences between the two countries both in the relations of the variables and the level of them.

Testing the first hypothesis showed that prior knowledge as demonstrated in the pre-test was clearly the strongest predictor of post-test performance in both countries. This corresponds to the earlier results regarding both learning in the science exhibition context [e.g Thuneberg, Salmi and Vainikainen, 2014] and the development of cognitive performance in general [e.g. Vainikainen, 2014]. However, the two countries differed in how strong this prediction was: in Sweden it was statistically significantly stronger than in Latvia. Also, the Swedish pupils scored in general considerably lower than the Latvian students but their performance was related to their general level of mathematical thinking skills, which was not the case in Latvia. Nevertheless, also in Latvia mathematical thinking skills slightly predicted post-test scores, indicating that pupils with more developed mathematical thinking skills benefitted more from the exhibition. This corresponds to the earlier results that pupils with better general reasoning skills learn slightly more during a science exhibition [Thuneberg, Salmi and Vainikainen, 2014], but the results of the present study show that the mechanism of it may to some extent be topic-specific. That is, mathematical thinking skills facilitated learning of mathematical exhibition contents. In general, there is evidence that high cognitive performance on a general level facilitates domain-specific learning, but when learning is based on already acquired skills, the improvements are often domain-specific too. However, domain-specific learning also influences the development of the more general cognitive mechanisms, which over time may strengthen the connection between domain-general and domain-specific performance [cf., Demetriou, Spanoudis and Mouyi, 2011; Gustafsson, 2008; Vainikainen et al., 2015].

This also applies to more mathematics-specific situations: the mastery of foundational concepts of numbers allows for a deeper understanding of more complex mathematical problems and flexible problem-solving techniques [Duncan et al., 2007]. This means that learning can occur both from general to specific and the other way around.

Besides prior knowledge and mathematical thinking skills, mathematical self-concept was also a statistically significant predictor of post-test scores in both countries. The effect was very weak but it corresponded with the results of earlier studies, in which the added value of beliefs and affective factors have been studied by controlling first the general cognitive performance level [e.g. Gagné and St. Père, 2002; Steinmayr and Spinath, 2009] A little surprisingly, in Latvia self-concept was 
not related to prior topic-specific knowledge even though there was a correlation between it and mathematical thinking skills in both countries. It is possible that the contents of the exhibition and thus the contents of the pre-test were so far from traditional school mathematics in Latvia that the connection was not obvious enough for the pupils to produce any positive effect of mathematical self-concept on the results. However, the situation slightly changed during the exhibition as in both countries the pupils with higher mathematical self-concept learned slightly more. In general, the first hypothesis was supported only partially due to the weaker-than-expected relationships between many of the variables in Latvia.

The latter part of the study took a closer look at the country differences in regard to performance and self-concept. This revealed the magnitude of the difference between the two countries: When the pupils were divided in four equally sized groups based on their mathematical thinking skills, the Latvian pupils belonging to the lowest-performing group had approximately equal prior topic-specific knowledge and the development of the performance than the highest-performing Swedish group. This corresponds to the results obtained in the recent PISA cycles about the differences of these two countries [OECD, 2013b], not just regarding the performance level but also regarding mathematical self-concept, which despite of higher performance was more modest in Latvia. The differences between the performance subgroups were also smaller in Latvia than they were in Sweden. It is possible that the Latvian pupils put in general more effort on the tests, which could also explain their non-existing correlation to self-concept and pre-test results. Putting it the other way around, it is possible that the Swedish results tell more about what the pupils are willing to show in the test situation and not just their absolute competence [cf. Kupiainen et al., 2014]. But even though there were significant differences between the two countries, there were similarities, as well. The pupils learned approximately similar amounts much during the exhibition even though the Latvians started from a higher initial level. Also, the weakest performers improved their results in both countries, and the differences to the other groups regarding the improvement were not big. This is an important result as one of the main aims of out-of-school learning is to provide learning opportunities for the weakest learners and it has from the beginning been assumed that they would benefit particularly from such opportunities [see Resnick, 1987].

There is a lot everyday knowledge and anecdotes reported in the research literature [Driver, Guesne and Tiberghien, 1985; Görlizt, 1987; Driver et al., 1996; Falk and Dierking, 2002; SINUS, 2012; Fenyvesi, Koskimaa and Lavicza, 2015] related to the effectiveness of learning mathematics outside and especially before formal school education. There are a lot of everyday situations where people are using and understanding mathematics while solving small problems in a logical way. In addition, there are an enormous amount of examples where young people and adults cannot apply even the basics of the mathematical knowledge in everyday situations.

There were some limitations in the present study. First, when interpreting the country differences there may be some differences in the representativeness of the samples as the participation was voluntary on the school-level. Also, the topic-specific knowledge test was developed for the present study and there is no prior information of how it fits into the different cultures or curricula. However, Sweden and Latvia are both European countries and the cultural differences are not 
likely to be large. As the test was not supposed to measure curricular contents, it was considered as being more independent from the school context than the other topic-specific tests are.

\section{Conclusions}

The present study shows that novel mathematics-related phenomena can be taught to 12-year-olds in an out-of-school context. A science centre mathematics exhibition is an effective learning environment for pupils at all performance levels, even though the best mathematical thinkers benefit the most from the visit as well as pupils with the highest mathematical self-concept. Even though there are relatively large differences between Latvian and Swedish pupils, the results show that regardless of performance level, the pupils learn on average a similar amount from the exhibition. The results of the study give some of the first pieces of evidence of the effectiveness of out-of-school mathematics teaching in a science exhibition context, providing a good basis for further studies.

Everyday knowledge, empirical evidence, and the research literature [Ma and Kishor, 1997; Kondratieva, 2007; Fenyvesi, Koskimaa and Lavicza, 2015] indicate that people become easily motivated when mathematical connections are presented in ways which relate their experiences by triggering their natural curiosities and aesthetic sensibilities. Expanding interdisciplinary fields of research like visual mathematics, everyday solutions, ethno, ancient and historic mathematics, and inquiry-based learning of mathematics have proven to receive very encouraging solutions and results during the recent decades [Jablan and Radovic, 2011; Artigue and Blomhøj, 2013]. While trying to address the widening gap between the general mathematical competence and increasingly computational contemporary culture, the power of curiosity, art, imagination, and play [Görlizt, 1987] can be utilised as one of the most fundamental human traits. The science centre exhibition visited in the test was exactly an example of art meeting science and mathematics.

Adey, P., Csapó, B., Demetriou, A., Hautamäki, J. and Shayer, M. (2007). 'Can we be intelligent about intelligence?: Why education needs the concept of plastic general ability'. Educational Research Review 2 (2), pp. 75-97. DOI: 10.1016/j . edurev . 2007.05.001.

Artigue, M. and Blomhøj, M. (2013). 'Conceptualizing inquiry-based education in mathematics'. ZDM - The International Journal on Mathematics Education 45 (6), pp. 797-810. DOI: $10.1007 / \mathrm{s} 11858-013-0506-6$.

Baddeley, A. D. and Hitch, G. (1974). 'Working Memory'. Psychology of Learning and Motivation 8. Ed. by G. H. Bower, pp. 47-89. DOI: 10.1016/S0079-7421(08)60452-1.

Bandura, A. (1997). Self-efficacy: The exercise of control. New York, U.S.A.: W. H. Freeman.

Bitgood, S. (1988). A comparison of formal and informal learning. Technical Report No. 88-10. Jacksonville, AL, U.S.A.: Center for Social Design.

Braund, M. and Reiss, M. (2004). Learning science outside the classroom. London, U.K.: Routledge.

- (2007). 'What does out-of-school learning offer school science?' The Science Education Review 6, pp. 35-37. 
BRIDGES, (14th August 2014-19th August 2014). Bridges Seoul 2014. Mathematics, Music, Art, Architecture, Culture. Gwacheon National Science Museum, Seoul, Korea.

Carroll, J. B. (1993). Human cognitive abilities: A survey of factor-analytic studies. New York, U.S.A.: Cambridge University Press.

Chiu, M. and Klassen, R. M. (2010). 'Relations of mathematics self-concept and its calibration with mathematics achievement: Cultural differences among fifteen-year-olds in 34 countries'. Learning and Instruction 20 (1), pp. 2-17. DOI: 10.1016/j.learninstruc.2008.11.002.

Crane, V., Nicholson, H., Chen, M. and Bitgood, S. (1994). Informal Science Learning. Dedham, U.K.: Research Communications.

Curtain-Phillips, M. (1999). Math Attack: How to Reduce Math Anxiety in the Classroom, at Work and in Everyday Personal Use. Atlanta, U.S.A.: Curtain-Phillips Publishing.

Demetriou, A., Spanoudis, G. and Mouyi, A. (2011). 'Educating the Developing Mind: Towards an Overarching Paradigm'. Educational Psychology Review 23 (4), pp. 601-663. DOI: 10.1007/s10648-011-9178-3.

Demetriou, A., Platsidou, M., Efklides, A., Metallidou, Y. and Shayer, M. (1991). 'The development of quantitative-relational abilities from childhood to adolescence: Structure, scaling, and individual differences'. Learning and Instruction 1 (1), pp. 19-43. DOI: 10.1016/0959-4752 (91)90017-3.

Demetriou, A., Pachaury, A., Metallidou, Y. and Kazi, S. (1996). 'Universals and specificities in the structure and development of quantitative-relational thought: A cross-cultural study in Greece and India'. International Journal of Behavioral Development 19 (2), pp. 255-290.

Dillon, J., Rickinson, M., Teamey, K., Morris, M., Choi, M. Y., Sanders, D. and Benefield, P. (2006). 'The value of outdoor learning: evidence from research in the UK and elsewhere'. School Science Review 87 (320), pp. 107-111.

Discover the Art of Math (2012). 4Dframe workshops. URL: www . energiakeskus.ee/dam/4dwsh.php.

- (2014). Exhibition. URL: www . energiakeskus . ee/dam/news . php.

Driver, R., Guesne, E. and Tiberghien, A. (1985). Children Ideas of Science. Milton Keynes, U.K.: Open University Press.

Driver, R., Leach, J., Millar, R. and Scott, P. (1996). 'Young People's Images of Science'. American Journal of Education 105 (4), pp. 497-503. URL: http://www.jstor.org/stable/1085602.

Duncan, G. J., Dowsett, C. J., Claessens, A., Magnuson, K., Huston, A. C., Klebanov, P., Pagani, L. S., Feinstein, L., Engel, M., Brooks-Gunn, J., Sexton, H., Duckworth, K. and Japel, C. (2007). 'School readiness and later achievement'. Developmental psychology 43 (6), pp. 1428-1446.

Falk, J. (1982). 'Environmental education: formal vs. informal learning'. Environmental Education and Information 2 (3), pp. 171-178.

Falk, J. and Dierking, L. (2002). Lessons withour the Limit. Walnut Creek, CA, U.S.A.: AltaMira.

Faure, E., Herrera, F., Kaddoura, A.-R., Lopes, H., Petrovsky, A. V., Rahnema, M. and Champion Ward, F. (1972). Learning to be: The world of education today and tomorrow. Paris, France: UNESCO.

Fenichel, M. and Schweingruber, H. (2010). Surrounded by science: Learning science in informal environments. Board of Science education, Center of education, Division of behavioral and social sciences and education. Washington, DC, U.S.A.: The National Academic Press. 
Fenyvesi, K. (2012). 'The Experience Workshop MathArt Movement: Experience-centered Education of Mathematics through Arts, Sciences and Playful Activities'. In: Proceedings of Bridges World Conference. Towson University, Baltimore, U.S.A., pp. 239-246.

Fenyvesi, K., Koskimaa, R. and Lavicza, Z. (2015). Experiential education of mathematics: Art and games for digital natives.

Forman, S. L. and Steen, L. A. (2000). 'Making Authentic Mathematics Work for All Students'. In: Education for Mathematics in the Workplace. Ed. by A. Bessot and J. Ridgway. Dordrecht, Netherlands: Kluwer Academic, pp. 115-126.

Frantz-Pittner, A., Grabner, S. and Bachmann, G. (2011). Science Center Didaktik. Hohengehren, Germany: Schneider Verlag.

Gagné, F. and St. Père, F. (2002). 'When $\{\mathrm{IQ}\}$ is controlled, does motivation still predict achievement?' Intelligence 30 (1), pp. 71-100. DOI: 10.1016/S0160-2896(01)00068-X.

Gardner, H. (1991). The unschooled mind. How children think and how schools should teach. New York, U.S.A.: Basic Books.

Geary, D. C. (2011). 'Cognitive predictors of achievement growth in mathematics: A 5-year longitudinal study'. Developmental Psychology 47 (6), pp. 1539-1552. DOI: 10.1037/a00255201110.

Görlizt, D. (1987). Curiosity, Imagination, and Play: On the developmental of the spontaneus cognitive and motivational processes. New Jersey, U.S.A.: Lawrence Erlbaum.

Gustafsson, J. (1984). 'A unifying model for the structure of intellectual abilities'. Intelligence 8 (3), pp. 179-203. DOI: http://dx.doi.org/10.1016/0160-2896(84)90008-4.

- (2008). 'Schooling and intelligence: Effects of track of study on level and profile of cognitive abilities'. In: Extending intelligence. Enhancement and new constructs. Ed. by R. D. R. P. E. Kyllonen and L. Stankov. New York, U.S.A.: Routledge, pp. 31-50.

Hein, H. (1990). The Exploratorium. The Museum as Laboratory. Washington D.C., U.S.A.: The Smithsonian Institution.

Illich, I. (1971). Deschooling society. New York, U.S.A.: Harper and Row.

Jablan, S. and Radovic, L. (2011). 'Do you like paleolithic op-art?' Kybernetes 40 (7/8), pp. 1045-1054. URL: http://www . emeraldinsight. com/journals.htm?ar ticleid=1949410\&show=html.

Jansen, T. (2007). My creations. A new form of life. URL: www.ted.com/talks/theo $\backslash_{-}$jansen $\backslash_{-}$creates $\backslash$ nnew $\backslash$ _creatures.

Kline, R. (2005). Principles and practice of structural equation modeling. 2nd ed. New York, U.S.A.: Guilford Press.

Kondratieva, M. (2007). 'Understanding mathematics through resolution of paradoxes'. Mediterranean Journal for Research in Mathematics Education 6 (1/2), pp. 127-138.

Kupiainen, S., Vainikainen, M.-P., Marjanen, J. and Hautamäki, J. (2014). 'The role of time on task in computer-based low-stakes assessment of cross-curricular skills'. Journal of Educational Psychology 106 (3), pp. 627-638. DOI: 10.1037/a0035507.

$\mathrm{Ma}, \mathrm{X}$. and Kishor, N. (1997). 'Assessing the relationship between attitude toward mathematics and achievement in mathematics: A meta-analysis'. Journal for Research in Mathematics Education 28 (1), pp. 26-47.

Marsh, H. (1990). 'The structure of academic self-concept: The Marsh/Shavelson model'. Journal of Educational Psychology 82 (4), pp. 623-636. 
Marsh, H. W., Byrne, B. M. and Shavelson, R. J. (1988). 'A multifaceted academic self-concept: Its hierarchical structure and its relation to academic achievement'. Journal of Educational Psychology 80 (3), pp. 366-380.

Melton, A., Feldman, N. and Mason, C. (1936). Experimental studies in education of children in a museum of science. Studies in Museum Education. Classical Reprint. Washington D.C., U.S.A.: American Association of Museums.

Newsom, B. and Silver, Z. (1978). The Art Museum as Educator. A collection of studies as guides to practice and policy. Berkley, U.S.A.: University California Press.

OECD (2013a). PISA 2012 Results: Ready to Learn: Students' Engagement, Drive and Self-Beliefs (Volume III).

- (2013b). PISA 2012 Results: What Students Know and Can Do - Student Performance in Mathematics, Reading and Science (Volume I).

Osborne, J. F. and Dillon, J. (2008). Science education in Europe. London, U.K.: Nuffield Foundation.

Persson, P.-E. (2000). 'Community Impact of Science Centers: Is There Any?' Curator: The Museum Journal 43 (1), pp. 9-17. DOI: $10.1111 / j .2151-6952.2000 . t b 01156 . x$.

Piaget, J. (1972). Psychology and epistemology: Towards a theory of knowledge. Harmondsworth, U.K.: Penguin.

Rennie, L., Feher, E., Dirking, L. and Falk, J. (2003). 'Towards an agenda for advancing research on science learning in out-of-school settings'. Journal of Research in Science Teaching 40 (2), pp. 112-120.

Resnick, L. B. (1987). 'The 1987 presidential address: Learning in school and out'. Educational Researcher 16 (9), pp. 13-54.

Salmi, H. (1993). Science Centre Education. Motivation and Learning in Informal Education. Research Report 119. Helsinki, Finland: Department of Teacher Education, University of Helsinki.

- (2003). 'Science centres as learning laboratories'. International Journal of Technology Management 25 (5), pp. 460-476.

- (2011). 'Evidence of bridging the gap between formal and informal learning through teacher education'. Reflecting Education 8 (2), pp. 45-61.

- (2012). 'Towards an open learning environment via Augmented Reality (AR): visualizing the invisible in science centres and schools for teacher education'. Procedia: Social and Behavioral Sciences 45 (2), pp. 284-95.

Salmi, H., Kaasinen, A. and Kallunki, V. (2012). 'Towards an Open Learning Environment via Augmented Reality (AR): visualising the invisible in science centres and schools for teacher education'. Procedia - Social and Behavioral Sciences 45, pp. 284-295.

Shayer, M. (1979). 'Has Piaget's construct of formal operational thinking any utility?' British Journal of Educational Psychology 49 (3), pp. 265-276. DOI: 10.1111/j.2044-8279.1979.tb02425.x.

SINUS (2012). Towards New Teaching in Mathematics. Ed. by C. M. P. Batist and D. Raab. Germany: University of Bayreuth.

Slavin, R. E., Lake, C. and Groff, C. (2009). 'Effective programs in middle and high school mathematics: A best-evidence synthesis'. Review of Educational Research 79 (2), pp. 839-911. DOI: 10.3102/0034654308330968.

Steinmayr, R. and Spinath, B. (2009). 'The importance of motivation as a predictor of school achievement'. Learning and Individual Differences 19 (1), pp. 80-90. DOI: 10.1016/j.lindif. 2008.05.004. 
Sternberg, R., Castejon, J. L., Prieto, M. D., Hautamäki, J. and Grigorenko, E. (2001). 'Confirmatory factor analysis of the Sternberg Triarchic Abilities Test in three international samples'. European Journal of Psychological Assessment 17, pp. 1-16.

Tan Wee Hin, L. and Subramaniam, R. (2003). 'Science and technology centres as agents for promoting science culture in developing nations'. International Journal of Technology Management 25 (5), pp. 413-426.

Thuneberg, H., Salmi, H. and Vainikainen, M.-P. (2014). 'Tiedenäyttely, motivaatio ja oppiminen [Science exhibition, motivation and learning]'. Psykologia 49 (6), pp. 420-435.

Vainikainen, M.-P. (2014). Finnish primary school pupils' performance in learning to learn assessments: A longitudinal perspective on educational equity. Report 360. Helsinki, Finland: Unigrafia.

Vainikainen, M.-P., Salmi, H. and Thuneberg, H. (2015). 'Situational Interest and Learning in a Science Center Mathematics Exhibition'. Journal of Research in STEM Education 1 (1), pp. 51-67.

Vainikainen, M.-P., Hautamäki, J., Hotulainen, R. and Kupiainen, S. (2015). 'General and specific thinking skills and schooling: Preparing the mind to new learning'. Thinking Skills and Creativity, in press. DOI: 10.1016/j.tsc.2015.04.006.

White, H. (2014). Our Education System is not so much "Broken" - as it is Totally Outdated! URL: http://steam-notstem.com/articles/our-education-systemis-not-so-much-broken-as-it-is-totally-outdated/.

\section{Authors}

Professor Hannu Salmi (born 1957) works currently as a Research Director in the University of Helsinki, Department of Teacher Education. Before that he held a position as Professor of Science Communication in Sweden at the University of Dalarna. For more than three decades (since 1984) he has been working as the Manager of Research and Development in Heureka, the Finnish Science Centre developing the IBSE orientated, practical hands-on science learning. He has also wide experience of more than 20 EU-funded projects also coordinating several EU-funded science education projects like Hands-on \& Brains-on, Open Science Info and Science Centre to go. The main interest of the research of professor Salmi is open learning environments, informal education, intrinsic motivation, career choices, and teacher training. He has also been the member of the EU-DG Research Advisory Board of the Science In Society Program; and as well the invited expert member of the STM-Science Technology Mathematics Cluster by EU-DG Education. He was the key expert while creating the memo "Science Education in Finland 2020 and Beyond" by Ministry of Education. E-mail: hannu.salmi@helsinki.fi.

Mari-Pauliina Vainikainen has a Ph.D. in special education with a thesis about the development of primary school pupils learning to learn skills and the factors influencing their performance in educational assessment studies. She is a licenced psychologist who has worked as the project manager of the Centre for Educational Assessment at the University of Helsinki since 2007 and researcher since 2002. She coordinates the large-scale municipal and nationally representative assessment studies conducted at the Centre, and she also participated in the national implementation of PISA2006. In PISA 2015 she acts as the vice-NPM for Finland, having the responsibility of the core domain of collaborative problem solving. In 2007-2012 she coordinated the work of The Scientific Board of Psychology in Finland, preparing evidence-informed recommendations for developing practices. She is also the editor-in-chief of Psykologia (The Finnish Journal of Psychology). E-mail: mari-pauliina.vainikainen@helsinki.fi. 
Ph.D. Helena Thuneberg works ain the University of Helsinki, Dept. of Teacher Education, spezialised in the special education as senior lecturer. Her main research focus is in the motivation, self-concept, and learning. Recentely, she has been working in the field of science education and informal learning.

E-mail: helena.thuneberg@helsinki.fi.

How to cite

Salmi, H., Vainikainen, M-P. and Thuneberg, H. (2015). 'Mathematical thinking skills, self-concept and learning outcomes of 12-year-olds visiting a Mathematics Science Centre Exhibition in Latvia and Sweden'. JCOM 14 (04), A03.

This article is licensed under the terms of the Creative Commons Attribution - NonCommercial NoDerivativeWorks 4.0 License.

ISSN 1824 - 2049. Published by SISSA Medialab. http:/ /jcom.sissa.it/. 